\title{
An Investigation of the Misuse of English Articles of Chinese English Learners*
}

\author{
ZHOU Xia, Du Yan-xia \\ North China Electric Power University, Baoding, China
}

\begin{abstract}
English articles belong to a category of high frequency words. However, they also have been considered as one of the most difficult part and latest part to be fully acquired by non-native speakers. Because of this reason, a lot of efforts have been made to research into the acquisition of them. In China, researches on the article system were mainly focused on the analysis of functions and description of the usage. This essay intends to explore the distribution and features of English article errors made by Chinese EFL (English as a Foreign Language) learners both horizontally and longitudinally with the hope to find the possible factors which lead to the errors, so as to throw some light on English articles learning and teaching.
\end{abstract}

Keywords: article, error analysis, article system, English proficiency, negative transfer

\section{Introduction}

English articles are among the most frequently used words in English language. They appear in almost all English sentences and are therefore usually introduced firstly to ESL (English as a Second Language)/EFL learners in their adventures of the new language. They look simple. They are easy to write and to remember. However, the power they own is really not that small as they look. They have already become one of the number-one headaches for Chinese English learners. Some of them take years to become proficient in the proper use of them. Some simply give up hope to acquire the proficiency to use it properly. As an ESL teacher, I was often asked to go through the research papers of some young scholars who specialize in fields other than English. The wrong use of the articles ranks the top error. Some even tell me frankly that the only uncertainty about their papers is that they are not sure of the use of the articles.

As we all know, Chinese language is generally acknowledged "as a language with no functional equivalent of the English article system" (LI \& YANG, 2010). In Chinese language, definiteness and indefiniteness are made apparent by word order or by the use of determiners such as 这 (pronounced "zhe" which stands for this), 那 (pronounced "na" which stands for that, and - (pronounced "yi" which stands for one). For Chinese speakers, these seemingly simple morphemes, the, a/an, and zero article in English are real problems, and are usually not mastered until a very late stage of their English learning. In fact, most of the Chinese EFL

\footnotetext{
* Acknowledgements: This article is one of the results of the Teaching Reform Project of Higher Education in Hebei in 2015 (No.: 2014YYJG282).

ZHOU Xia, associate professor, master, English Department, North China Electric Power University.

Du Yan-xia, lecturer, master, English Department, North China Electric Power University.
} 
learners could never know for sure how to use them in some of the cases.

It is because of this reason that the acquisition of the English article system by Chinese learners has always been the focus of scholars of English language learning and teaching in China in recent years (LI \& CAI, 2001; YAN, 2003; WANG, 2005; CAI \& WU, 2006; CAI, 2007; ZHOU, 2007; ZHU \& WEN, 2008a, 2008b, 2008c). Some of the studies, however, are mainly concerned with the analysis of the syntactic or semantic functions of English articles ( like ZHOU). Some focus on the the issue of acquisition patterns. There were, of course, some studies related to analysis of errors Chinese learners made and the problems they met in learning. They were either about a specific group of learners (e.g., English-majors, posgraduates), or conerned with the article usage in a certain aspect (e.g., LI \& CAI in writing). And the studies on the miuse of English articles are also limited to descriptive perspective. Emperical studies on the errors made by Chinese EFL learners in English articles acquisition in general are relatively rare. Hence, this article aims to explore the error types, to analyze the sources of the errors and to probe into the specific barriers that the Chinese EFL learners encounter during the learning process. At last, the pedagogical implications of our findings are to be identified to provide some suggestions for teaching and learning of English articles.

\section{The Purpose of the Study}

The purpose of this study is to answer at least the following questions concerning the English Articles' Acquisition by Chinese EFL learners.

(1) What is the present general status of the English Articles' Acquisition of Chinese EFL learners?

(2) What are some of the chief problems Chinese EFL learners encounter in their English Articles' Acquisition?

(3) What is the relationship between Chinese EFL learners' English proficiency and their article acquisition?

(4) What are the typical errors Chinese EFL learners committed in their use of the target language?

(5) What factors influence the English article acquisition by Chinese EFL learners' and are the possible causes of the learners' misuse of the articles?

To sum up, the ultimate aim of this study is to get a better understanding of the problems that Chinese EFL learners have and the typical errors they make in their acquisition of English articles, so as to deepen our understanding of how Chinese EFL learners acquire the English article system in the Chinese context and offer some constructive suggestions for the learning and teaching of English articles.

\section{Methodology}

\section{Subject}

The study involves 120 Chinese EFL learners. These people are divided into three groups mainly according to the time they study English to represent three different language proficiency levels: the low level group, the intermediate level group, and the advanced level group.

The low level subjects are some junior one middle school students. They have approximately studied English for one year. Their average age is 13 . The intermediate level subjects are high school senior two students who have studied English for about four or five years. The age of these students is from 14 to 16 . The advanced 
level students are non-English majors from a college. They are treated as high level students because they have studied English for more years and have scores more than 115 points in the English college entrance examination. The average age of this group of students is 19 .

\section{The Instruments}

Two tests were employed in this study: the English proficiency test and the article test. The English proficiency test intends to examine the participants' English level and their English competency. The article test aims to find out the article acquisition situation of them. And an interview is also made after the tests.

\section{The English Proficiency Test}

The English proficiency test consists of multiple choices, reading, and translation. It is designed to check the English proficiency of the three groups of participants. The students are supposed to complete the test independently within 30 minutes.

\section{The Articles Test}

This test includes filling blanks and error corrections. Hopefully, we can testify how much the English proficiency influences the use of the articles. We also hope to find out what kind of errors the Chinese EFL learners often make, and by analyzing the mistakes, we can figure out the reasons for making them. The participants are allowed 30 minutes to finish all the questions

There are all together 120 students who take part in both the two tests. The valid test papers are 96 respectively. After the tests, 10 students from each group are interviewed.

\section{The Interview}

Interviews are a standard part of qualitative research. They are far more personal forms of research. In this investigation, interviews provide an opportunity of face-to-face interaction with the subjects. In the interviews, we work directly with the participants, listen to them, and ask questions to clarify the root of the misuse of the English articles. We ask questions like which article is comparatively difficult for them to grasp and why? We also ask them to explain why they make certain choice in the test paper. The interviews are certainly helpful for us to understand what the subjects were experiencing.

\section{Data Analysis}

Table 1

The Misuse of English Articles of Chinese EFL Learners

\begin{tabular}{llll}
\hline Error types & Students of low level & Students of intermediate level & Students of advanced level \\
\hline Confused use of a (an)/the & 44.9 & 21.7 & 19.5 \\
Omission of articles & 48.4 & 22.3 & 20.6 \\
Redundancy of the & 9.2 & 11.8 & 12.0 \\
Redundancy of a (an) & 31.4 & 7.0 & 6.4 \\
\hline
\end{tabular}

Through careful analysis we find that,

(1) The misuse of articles is one of the most commonly made mistakes of Chinese EFL learners. It is the mistake that students of almost all level of language proficiency are likely to make;

(2) The study shows that the acquisition of English articles is positively related with the EFL learners' language proficiency. Generally speaking, the higher the learners' English proficiency is, the better acquisition 
they have of the English articles. In another words, the learners of lower English proficiency are more likely to make more article errors;

(3) Generally speaking, the types of article errors that Chinese EFL learners make roughly fall into three categories: redundancy, omission, and confusion. Among all these three types of errors, omission takes up the highest proportion $(48.4,21.7,19.5)$ in all three levels of students, followed by confusion $(44.9,21.7,19.5)$, and finally redundancy $(9.2,11.8,12.0)$. In addition, the order of Chinese EFL learners' mastery of English articles turns out to be the $>$ a/an $>\Phi($ see Table 1$)$.

\section{Discussion}

Error Analysis studies the types of errors made by EFL learners and the causes for making those errors. It was Corder (1918-1990) who first made Error Analysis (EA) occupy a place in applied linguistics. "It was not until the 1970s that EA became a recognized part of applied linguistics, a development that owned much to the work of Corder" (1967, p. 56) Rod Ellis said (1994). It was Corder who first told people to whom information about errors would be helpful and how.

\section{The Discussion of Omission of Articles}

Our study suggests that omission error is one of the most frequent errors that the Chinese EFL learners of the three language proficiency levels make. Omission of articles refers to the occasions that no articles are used when the use of articles are needed actually. In most cases, a noun or noun phrase in English must be "completed" with a determiner to express the reference of that noun or noun phrase in the context. The common English determiners are the definite article and the infinite articles a (an). However, these articles are absent in Chinese. And this absence of the articles often generates a negative transfer in their use of the target language, making them forget to use the English articles in reality. In the sentence: In _ 1960s, there were a lot of protests against the Vietnan War, a high percentage of the subjects committed this error; they chose zero article for this blank; and the rate is higher with the lower English proficiency level students. In another sentence: What is _ diameter of _ moon? The Chinese students also chose zero article before the word "moon". In the interview after the tests, when asked about the strategies they used to deal with the conundrum they faced while doing the tests, most of the students admitted that they translated the sentences into Chinese first and then made the choices. In the second example above, when asked to account for why they chose zero article, most of the subjects admitted that the reason for this was that Chinese people did not use determiner before this word. So here again, the knowledge of the native language becomes a big barrier. Judging from the statistics (see the Table 1), the rate of the errors is getting lower as the learners' level of English proficiency is getting higher. This also suggests that as they learn more, the influence of the negative transfer drops off.

\section{The Discussion of Confusion}

Confusion of articles is the circumstance where an incorrect article is used instead of the correct article. This error ranks the second in the list. From the data collected, we can find that 44.9 percent of the students from the junior one middle school made this kind of mistakes, while the number becomes 21.7 for the high school senior two students, and as for the non-English majors from a college, the number becomes 19.5. This shows the popularity of the confusion among Chinese EFL learners. The depressive trend in this aspect shows that with 
development of the study, the growth of the relative knowledge and the mastery of the article will gradually improve.

Compared with the omission errors, the subjects made less confusion errors. Their confusion of the English articles can be mainly divided into two categories: the confusion of "a" and "the"; the confusion of "a" and "an".

After careful analysis and some interviews with the subjects, we come to the conclusion that the main cause of this error is Inter-lingual Transfer for the Chinese EFL learners. Inter-lingual transfer refers to the transfer from the first language. Before rules of the foreign language are required, the first language is the only language system from which the learners can draw experience. When these students begin to learn the rules of a new language, there is always an underlying assumption that the rules of the new language are in accordance with that of the native language. Even the students who know for sure that the two languages may have different rules may unconsciously use the native rules in the use of the new language. In the interview after the test, some subjects admitted that they made decisions from "the sense of the target language", and they also claimed that when they made up their mind they tended to use the "knowledge of Chinese language". The conclusion we can draw from this is that the underlying Chinese grammar rules are always acting during the process that the Chinese EFL learners are using the new language. Especially when they have not had a good command of the new rules of English language, they make more mistakes.

It is clear that a poor command of the new grammar is also crucial. Generally speaking, the confusion of "a" and "the" mostly results from the failure in the distinction of specific reference and generic reference. On the one hand, some subjects use definite article "the" when indefinite article "a" is required. For example, in the sentence: Isaac Newton is a man of great intelligence, some students chose "the" instead of "a". Here, obviously, "man of great intelligence" is the generic descriptive post modified, therefore " $\mathrm{a}$ " is necessary. In the sentence: There is a John or Jim Smith waiting for you, many subjects chose "the". It is obvious that they have confused the difference between specific reference and generic reference. In this sentence, John or Jim Smith is a generic, an indefinite concept indicating that a man called John or Jim Smith is waiting. On the other hand, some subjects choose "a" in a sentence where "the" is required. Like in the sentence: These tracks are made by _ spotted jaguar. 54\% of the students have used "a" for the blank. However, the correct choice should be "the". Here "the" spotted jaguar" is used to indicate a generic abstract. Compared with the confusion of "a" and "the", the confusion of "a" and "an" is relatively less. The study also shows that the lower English proficiency level participants make more such errors than the other two groups.

\section{Redundancy}

Redundancy of articles is that learners use articles in the situation where articles should not appear. From the above statistic description, we can see articles redundancy takes lowest percentage among the three kinds of errors; however, this kind of misuse of articles is more complicated. Chinese scholar LI and CAI (2001) mainly studied the misuse of articles of Chinese students in writing through the corpus-based approach combined with qualitative and quantitative analysis. Based on their research, the redundancy can be divided into five categories. We can find all the redundancy phenomena in our study, too. The phenomena are as follow: (1) overuse of the before ordinal numbers and cardinal numbers. Our viewpoint is in accordance with LI and CAI's to the reason why learners overuse the before ordinal numbers and cardinal numbers is they over generalize the principles of 
ordinal numbers, or do not master the exceptions usage, or even do not distinguish ordinal numbers from cardinal numbers; (2) overuse of articles in fixed phrases. The phenomenon is due mainly to the incomplete grasp and false memory of fixed phrases. Besides, learners have the tendency to add articles before nouns, which can be explained by overgeneralization; (3) overuse of articles before general nouns, absent nouns, and modified nouns. Through analysis, the redundancy here is possibly because of misunderstanding about usage of articles. Additionally, sometimes learners cannot fully identify what absent nouns are, what concrete nouns are, or what general nouns are, and what specific nouns are; (4) overuse of the before some language names and proper nouns. In this study, only the students of low level make the mistake. This is mainly due to the short time of studying English; and (5) overuse of articles before adjectives. This error is supposedly because learners cannot tell part of speech and mistake adjectives for nouns. Meanwhile, this phenomenon also reflects the affect of learner's mother language. In Chinese some adjectives can be used as nouns, subsequently learners make the error because of Chinese mode of thinking.

\section{Conclusion and Implications}

English articles are catigorized as particles and are called grammatical particles. One of the reasons for this is probably that they are so small, containing one, two, or three letters. They do not have their own lexical definition. They must be associated with another word or phrase to impart meaning. However, they appear frequently in sentences and are of great importamce in understanding the meaning because of their special functions in the sentences and because they indicate the type of reference being made by the nouns. Therefore, they should never be ignored by learners as well as teachers.

A comprehensive analysis of the data and the results of the tests paper show that Chinese EFL learners' knowledge of the English articles is basically incomplete. Leaners of varoius English profeciency level tend to make diferent errors,even the most advanced learners make errors in their usage of the articles. So English articles are extremely hard for Chinese EFL learners to grasp completely.

According to our investigation and analysis, the errors Chinese EFL learners made can be mainly classified into three categories: ommnission, confussion, and redundancy. Statistics of the collected data showed that ommission of articles took up the majority of the subjects"s errors, followed closely by errors of redundancy. The confusion of articles occupied the smallest proportion of errors.

The factors that influence Chinese EFL learners' acquisition of the English articles are complex and varied. But the main reasons as we analyse it might be the following three: firstly, the typological difference between English and Chinese. As we all know, Chinese does not contain an article system. That is to say, the English articles are a category of zero contrast for Chinese learners of English. According to previouse studies, the zero contrast may delay passage through a developmental sequence of Chinese EFL learners' article acquisition by adding a preliminary stage for them. Another typological difference between English and Chinese is that English is a sentence-oriented language while Chinese is a discourse-oriented language. There is a strong tendency for Chinese EFL learners to accept the forms that are acceptable in their own language and reject those that are unfamiliar to them. Generally speaking, in some obligatory contexts, learners of advanced English preficiency level can use articles somewhat correctly and make fewer mastakes, whereas in some non-obligatory contexts, it becomes difficult for learners of all English proficiency levels to decide what to use. 
Thirdly, the learners personal factors matter a lot in their English articles acquisition, too. These may include the learners' age, the learners' features, and their congnitive learning style. The learners' English profeciency level and their knowledge of English culture play a crucial role in their acquisition of English articles, amang other things.

Based on the above discussion, our pedagogical implications for both the learners and teachers are:

(1) To strengthen the input of English article knowledge, Viewed from a cognitive perspective, centering on input processing, low-frequency uses of articles are likely to be attended to by the learners. Just as Schmidt (1990) points out that other things being equal, the more frequent a form, the more likely it is to be noticed and then become integrated in the interlanguage system. Therefore, some specific methods should be adopted aiming at increasing the frequency of occurrence of English articles which are low in communicative values and are likely to be neglected; (2) To help Chinese learners develop knowledge of the English articles, emphasis must be given to the focus-on-form instructions. This is because Chinese learners tend to process input for meaning rather than for form. As English articles in many cases are redundant in expressing meanings, they are thus the most likely words to be unnoticed especially by Chinese EFL learners who possess a fixed mindset of a discourse-oriented language structure. A focus-on-form can remedy this effectively; and (3) Article acquisition cannot merely deal with articles proper. As articles are always used along with nouns, the teaching and the studying should be on nouns, especially on their referential properties.

\section{References}

Berry, R. (1991). Re-articulating the articles. ELT Journal, 45(3), 252-259.

CAI, J. T., \& WU, Y. A. (2006). A study of Chinese university students' use of English articles. Foreign Language Teaching and Research, 38(4), 243-250.

CAI,Y. L. (2007). On the use of the definite article in English by Chinese learners in their interlanguage. EFLEA Journal, 1, 111-118.

Corder, S. (1967). Idosyncratic errors and error analysis. International Review in Applied Linguistics, 9(2), 56-159.

Chomsky, N. (1995). The mininalist program. Cambridge, MA: MIT Press.

DAI, W. D., \& WEI, L. (2008). A study of the acquisition of English article semantics by Chinese learners. Foreign Language Teaching and Research, 40(2), 136-142.

Ellis, R. (1985). Understanding second language acquisition. Oxford: Oxford University Press.

Hawkins, J. A. (1978). Definiteness and indefinteness. London: Groom Helm.

LI, H. Y. (2010). An investigation of English articles' acquisition by chinese learners of English. Chinese Journal of Applied Linguistics, 33, 15-31.

LI, J. Q., \& CAI, J. T. (2001). The misuses of the English articles in compositions of Chinese college students-a corpus-based study. Journal of PLA University of Foreign Language, 6, 58-62.

Liu, D., \& Gleason, J. I. (2002). Acquisition of the article by the nonnative speakers of English : An analysis of four nongeneric uses. Studies in Second Language Acquisition, 24, 1-26.

Lu, F. C. (2001). The acquisition of English articles by Chinese learners. Second Langusge Studies, 20, 43-78.

Master, P. (1990). Teaching the English articles as a binary system. TESOL Quarterly, 24, 461-478.

Master, P. (1997). The English article system: Acquisition, function,and pedagogy. System, 25(2), 215-232.

Schmidt, R. (1990). The role of consciousness in second language learning. Applied Linguistics, 11, 17-46.

WANG, J. (2005). Acquisition of nongeneric uses of the English definite articles by Chinese learners. Foreign Language Education, 3, 22-26.

YAN, L. L. (2003). A corpus-based study of Chinese learners' acquisition of English articles. Foreign Language Teaching and Research, 3, 210-214.

ZHOU, B. G. (2007). A study of the overgeneralization in second language acquisition. Modern Foreign Languages, 4, $387-394$. 
ZHU, Y. Q. (2003). A survey of Chinese ESL learners' knowledge of the English article system. Foreign Language Teaching and Research, 5, 206-209.

ZHU, Y. Q., \& WEN, Q. F. (2008a). Factors prediction accurate use of the zero article on oral English: A study of tetiary-level Chinese EFL learners. Modern Foreign Languages, 4, 399-405.

ZHU, Y. Q., \& WEN, Q. F. (2008b). The research of articles in college students' oral English. Foreign Language Education, 3 , 61-63.

ZHU, Y. Q., \& WEN, Q. F. (2008c). A study of article use in oral English by learners of different proficiency levels. Journal of PLA University of Foreign Languages, 6, 39-41. 